\title{
Quantitative Risk-Benefit Analysis of Probiotic Use for Irritable Bowel Syndrome and Inflammatory Bowel Disease
}

\author{
William E. Bennett, Jr., M.D.
}

Assistant Professor of Pediatrics, Department of Pediatrics, Section of Pediatric Gastroenterology, Hepatology, and Nutrition, Section of Children's Health Services Research, and Section of Pediatric and Adolescent Comparative Effectiveness Research, Indiana University School of Medicine, Indianapolis, IN, USA

Please address correspondence to:

William E. Bennett, Jr. M.D.

webjr@iu.edu

410 W. $10^{\text {th }}$ Street

Indianapolis, IN 46202

317-278-0552

\section{Key Points}

1. Probiotics are widely used in both IBS and IBD, but published evidence is mixed for both safety and efficacy, and studies are very heterogenous. In general, the frequency of ADE and the efficacy are both close to placebo.

2. The risk-benefit plane for both IBS and IBD is broad. In IBS, most of the confidence region on the riskbenefit plane favors avoiding probiotic use. In IBD, most of the confidence region favors using probiotics.

Word count (text) $=4286$

Word count (abstract) $=241$ 


\section{ABSTRACT}

Probiotics have seen widespread use for a variety of gastrointestinal problems, especially in two common disorders: irritable bowel syndrome and inflammatory bowel disease. Since a wide variety of probiotic preparations has been used, and despite a large number of studies performed, a great deal of heterogeneity exists among them. Straightforward evidence-based recommendations for the use of probiotics in irritable bowel syndrome and inflammatory bowel disease have thus been difficult to formulate. In an effort to improve understanding of the risk-benefit balance of probiotics in these conditions, we (1) queried the FAERS database for all reported adverse drug events related to probiotics in 2013, and (2) constructed risk-benefit planes for both irritable bowel syndrome and inflammatory bowel disease using a geometric approximation of the confidence region between risk and benefit. Our results show that adverse events from probiotics vary widely by disease, and when they occur, they are mild and may be difficult to distinguish from the natural history of the underlying disorders they are used to treat. The risk-benefit plane for irritable bowel syndrome straddles the risk-benefit threshold, so patients can expect a balance between a low chance of risk and also a low chance of benefit. The risk benefit-plane for inflammatory bowel disease largely lies above the risk-benefit threshold, so patients may expect more benefit than risk in most cases. More standardized and high quality research is needed to improve our understanding of risk and benefit for these complex biopharmaceuticals. 


\section{BACKGROUND}

The use of probiotics has substantially increased over the past decade, more than quadrupling from 2007 to 2012.(1) The World Health Organization defines probiotics as "live organisms which when administered in adequate amounts confer a health benefit on the host,"(2), but the term is often used in situations for which no health benefit has been proven. As such, interest has increased in fostering clinical research to add the weight of evidence to this unique biopharmaceutical. If one searches MEDLINE with the term "probiotics", and results are limited to clinical trials, over 1400 clinical studies have been indexed, and more than 1200 of these have been performed in the past ten years. Given the heterogeneous and complex nature of probiotics as a drug, there is a great deal of heterogeneity in study design(3), and while there are many published trials, only a small percentage of them are of high methodological quality. Perhaps most concerning, however, is that probiotics tend to be lumped into a single category, despite representing a diverse group of organisms with wide differences in biological effect.(4) Yet even when they are considered separately, since most probiotics are regulated as supplements by the United States Food and Drug Administration and other governmental agencies worldwide,(5) there is often no guarantee they contain what they say they do.(6)

Naturally, diseases of the gastrointestinal tract are the most commonly studied. Some of the first disorders treated with probiotics have been those thought to be the direct result of an intestinal dysbiosis, or an abnormal and harmful fluctuation of intestinal bacterial populations. Most effectively studied has been the prevention of antibiotic-associated diarrhea $(7,8)$ shortening duration of acute infectious diarrhea,(9) and preventing recurrent Clostridium difficile infection(10). In such cases, probiotics tend to have a high benefit-risk ratio, mostly owing to relatively low risk,(11) but benefit may also often be low as well, especially with larger, more rigorous clinical trials.(7) Given the abovementioned disorders' association with dysregulation of the human microbiome, interest has mounted in the use of probiotics to treat both irritable bowel syndrome (IBS), and inflammatory bowel disease (IBD). While dysbiosis remains a likely,(12-14) but as yet poorly understood mechanism for IBD and IBS, this has not stunted the a priori assumption by many clinicians and patients that probiotics may be helpful. 
IBS is a functional gastrointestinal disorder (FGID) that is extraordinarily common throughout the world, occurring in roughly $10 \%$ of humans from childhood to late adulthood.(15, 16) The FGID clinical guidelines, known as the Rome III criteria(17), define IBS as abdominal pain or discomfort occurring at least 3 days per month over the preceding 3 months with at least two of the following associated symptoms: improvement with defecation, change in frequency of stool, or change in form or character of stool. The cause is unknown, although a complex etiology with both neurological and intestinal inputs is likely.(18) Therapy typically consists of some combination of dietary changes,(19) antispasmodic medications,(20) or other adjunctive pharmacotherapy or psychotherapy.(21) Probiotics are frequently tried for IBS, either at the advice of a clinician, or over-the-counter by the patient.

Inflammatory bowel disease comes in two general clinical phenotypes: ulcerative colitis (UC) and Crohn disease (CD). UC results in mucosal inflammation confined to the colon, usually in a contiguous fashion beginning in the rectum. Alternatively, $C D$ can involve any portion of the gastrointestinal tract and can extend through the entire intestinal wall. While their etiologies are unknown, they are both likely related to a dysregulated interaction between the normal intestinal microbiota and the host immune system.(12, 13)

Probiotics have been difficult to study(3), largely because they defy typical drug classification in many settings: probiotics are complex organisms taken as medications. As such, existing experience with drug safety and efficacy trials may be insufficient to study them. The assessment of risk and benefit for probiotics is also quite complex, since probiotics do not represent a single chemical compound, but a range of diverse live organisms with an even wider range of dynamic biological activities. Pharmacokinetic and pharmacodynamic considerations are also challenging to assess,(22) since each microbial population may constitute thousands of different active biological molecules.

We seek to provide guidance to clinicians and others caring for patients with IBS and IBD in regards to the riskbenefit balance for the use of probiotics in these disorders. We have grouped this guidance into three main sections below:

(1) A summary of the literature describing both risk and benefit of probiotics and IBS and IBD, 
(2) A description of the adverse drug events (ADEs) for all probiotics in the FDA's primary reporting service

(3) A quantitative analysis using a combination of systematic literature search of relevant trials, pooling of these existing data and simulation of 5000 patients, and then plotting of these simulated patients on a riskbenefit plane (RBP) to better visualize what we know about the risk-benefit balance for probiotics in these disorders.

\section{SUMMARY OF RISKS}

A previous systematic review by Didari and colleagues(23) focused on the risk of probiotics across all settings, and found that probiotics were generally safe, but found increased risk for immunocompromised patients, critically ill patients, and those at the extremes of age. Probiotics have been studied extensively for a broad variety of diseases, including IBS and IBD, yet rigorous assessment of adverse events has only rarely occurred in the many clinical trials performed.

IBS

Multiple recent controlled trials designed to assess efficacy have also assessed risk of adverse events, albeit heterogeneously. (24-38) Most trials had no adverse events reported at all. Most patients who reported ADEs reported mild symptoms, most often related to the gastrointestinal tract. Only three published trials assessed ADEs related to probiotics in IBS in any systematic or standardized way. $(27,29,34)$ A recent metaanalysis(39) showed a pooled relative risk (RR) for an adverse event of any type across all published trials of $1.21(95 \% \mathrm{Cl} 1.02-1.44)$ and number needed to harm was $35.16 .5 \%$ of patients in all trials had an ADE on probiotics, compared with $13.8 \%$ of controls. There were no deaths reported in any trials, and no serious adverse events such as cardiovascular or respiratory compromise reported.

\section{IBD}

As with IBS, multiple recent IBD trials designed to assess efficacy also addressed safety and ADEs as a secondary outcome(40-49). When these trials were pooled in a recent meta-analysis(50), there was no difference in ADEs in patients on probiotics versus controls, with a relative risk of 0.97 (95\% $\mathrm{Cl} 0.77-1.19)$. No trials reported patient deaths during the study period. Most reported ADEs were gastrointestinal symptoms. However, there was significant heterogeneity among trials, and some trials reported a wide confidence interval 
for relative risk of an ADE. As with IBS, there was a large degree of heterogeneity among trials in how they chose to measure ADEs, and only a single trial appears to have approached this measurement in a systematic and comprehensive way.(41)

Special Risk Cases - The Young, the Old, and the Immunosuppressed

Of special concern when introducing a biopharmaceutical containing live bacteria is that patients may develop infection from those bacteria due to impaired host immunity. Three populations are likely to be most affected in this scenario: (1) young children, especially neonates and preterm infants, (2) the elderly, and (3) patients on immunosuppressing medications.

Probiotics have been studied extensively in preterm infants in the context of necrotizing enterocolitis (NEC), a multifactorial necroinflammatory condition thought to have a basis in the interaction between microbiome and host immunity. These infants may be less likely to develop NEC(51-53), and while concern has long existed about probiotic strain-associated sepsis, this risk has not been born out in larger trials. However, studies overall have had mixed results $(54,55)$. Infants do not develop IBS, and develop IBD only in extremely rare cases, but the apparent safety of probiotics in this group is reassuring that the risk for vulnerable or immunocompromised patients may be relatively low.

The elderly represent a large number of patients with IBS and IBD, but the bulk of disease burden remains in young and mid-adulthood. Most clinical trials for IBS or IBD have included some elderly patients, but this demographic has been largely unstudied in relation to probiotics. No trials selected below for quantitative analysis specifically listed rates of ADEs in patients greater than 65 , and none had large numbers of elderly patients enrolled at all. No publications to our knowledge have specifically addressed the risks related to probiotic use in elderly adults for any disease.

Immunocompromised patients are of greatest immediate concern to clinicians prescribing probiotics, since many patients with chronic illnesses have IBS and many patients with IBD take immunosuppressants to manage the disease. Many of the trials included in our analysis have demonstrated no added risk to the 
addition of probiotics when patients are taking immunosuppressants such as thiopurines or biologics, but these studies are not designed to effectively determine safety of probiotics in the immunosuppressed host. A MEDLINE search using the terms "lactobacillus," "bifidobacteria," "saccharomyces", "VSL", or "probiotics" combined with "azathioprine," "mercaptopurine," "methotrexate," or "infliximab" did not produce any specific publications addressing the risks of probiotic use concurrently with these medicines. We thus conclude that no clear safety data exist to guide clinicians using both immunosuppressants and probiotics simultaneously.

The risk of sepsis from probiotics in all patients, even the immunocompetent, appears to be low, but non-zero. The prophylactic administration of probiotics has been associated with increased mortality in septic patients(56), so care should be taken before introducing probiotic regimens to severely ill patients. However, sepsis from a probiotic strain such as Lactobacillus remains very unlikely(57), even in at-risk patients.

\section{ADVERSE DRUG EVENTS (ADES)}

\section{Probiotics With Reported ADEs}

We queried the United States Food and Drug Administration's Adverse Drug Event Reporting System (FAERS)(58) for the entirety of 2013 and a relational database was built linking reported ADEs with drug names. Drug names associated with probiotic preparations were then isolated from this relational database, along with the case's associated adverse event(s). Generic terms and genus names ("probiotic", "lactobacillus", "bifidobacteria", and "saccharomyces") and the trade names (Align, Bio-K, Culturelle, DanActive, Florajen, Florastor, Kefir, Lactinex, ProBacLac, RepHresh, VSL \#3, and Yakult) for popular probiotic preparations in the United States were used to find probiotic-related ADEs. Counts of ADEs by probiotic type are shown in Table 1. These drug names only indicate which drug was reported in FAERS, and only show association with an ADE, not causation.

Table 1 - Number of each probiotic (and \% of total of 1165 probiotic-associated ADEs) in FAERS in 2013

Probiotic Type

Probiotic

Align

Lactobacillus

\section{Frequency}

799

132

87
$\%$

$68.6 \%$

$11.3 \%$

$7.5 \%$ 


$\begin{array}{lrr}\text { Florastor } & 65 & 5.6 \% \\ \text { Culturelle } & 44 & 3.8 \% \\ \text { Bifidobacterium } & 13 & 1.1 \% \\ \text { Saccharomyces } & 8 & 0.7 \% \\ \text { Florajen } & 6 & 0.5 \% \\ \text { Lactinex } & 6 & 0.5 \% \\ \text { VSL \#3 } & 2 & 0.2 \% \\ \text { Bioflor } & 1 & 0.1 \% \\ \text { Kefir } & 1 & 0.1 \% \\ \text { Rexell } & 1 & 0.1 \%\end{array}$

\section{Types of ADEs}

A total of 2,652,194 ADEs for all drugs were found in the FAERS in 2013. Among these, $1165(0.04 \%$ of all 2013 ADEs) were associated with probiotics according to the above search strategy (Table 2), but most ADEs only occurred once in a single patient, and there were 420 distinct event types enumerated. Among probiotics, the most commonly reported ADEs were abdominal pain (11\% of all ADEs), asthenia (3\%), and arthralgia (3\%). Two episodes of sepsis ( $0.2 \%$ of all ADEs), eight episodes of colitis ( $0.8 \%)$, and a single episode of Crohn disease $(0.1 \%$ of cases) were reported concurrently with probiotic use. Data on patients' other medications or medical history are not accessible in FAERS. In many cases, patients may have had significant polypharmacy, and adverse events were reported while taking multiple medications. These specific ADEs only indicate the symptom reported in FAERS, and only show association, not causation.

Table 2 - Most common specific adverse drug events in FAERS. All events listed in "Other" have 7 or less total occurrences. Some events could have co-occurred with other medications.

$\begin{array}{lrr}\text { Event } & \text { Frequency } & \% \\ \text { Abdominal pain } & 125 & 10.7 \% \\ \text { Drug ineffective } & 39 & 3.3 \% \\ \text { Arthralgia } & 34 & 2.9 \% \\ \text { Asthenia } & 30 & 2.6 \% \\ \text { Fatigue } & 29 & 2.5 \% \\ \text { Diarrhoea } & 28 & 2.4 \% \\ \text { Injection site pain } & 22 & 1.9 \% \\ \text { Injection site bruising } & 16 & 1.4 \% \\ \text { Anaemia } & 15 & 1.3 \% \\ \text { Anxiety } & 14 & 1.2 \% \\ \text { Crohn's disease } & 14 & 1.2 \%\end{array}$




$\begin{array}{lrr}\text { Alopecia } & 13 & 1.1 \% \\ \text { Cough } & 13 & 1.1 \% \\ \text { Dizziness } & 12 & 1.0 \% \\ \text { Back pain } & 11 & 0.9 \% \\ \text { Clostridium difficile infection } & 11 & 0.9 \% \\ \text { Flushing } & 11 & 0.9 \% \\ \text { Headache } & 10 & 0.9 \% \\ \text { Blood pressure increased } & 9 & 0.8 \% \\ \text { Dyspnoea } & 9 & 0.8 \% \\ \text { Colitis } & 8 & 0.7 \% \\ \text { Constipation } & 8 & 0.7 \% \\ \text { Contusion } & 8 & 0.7 \% \\ \text { Death } & 8 & 0.7 \% \\ \text { Incorrect dose administered } & 8 & 0.7 \% \\ \text { Injection site erythema } & 8 & 0.7 \% \\ \text { Other } & 646 & 55.5 \%\end{array}$

Therefore, ADEs are quite rare for probiotics (1165 events reported out of more than 2.6 million reported events in 2013), despite more than 4 million adults per month reporting taking probiotics.(1)

\section{SUMMARY OF BENEFITS}

IBS

Overall, current national guidelines are supportive of probiotics,(59) indicating more widespread use by gastroenterologists and primary care doctors to treat IBS. 15 trials met our criteria and were used further in the quantitative analysis below.(24-38) Overall, results were mixed, but the majority of trials showed some benefit. When the results of all published clinical trials were pooled in a recent meta-analysis(39), probiotics were effective at improving IBS symptoms, with an OR of 1.27 (95\% CI $1.12-1.42) .55 .8 \%$ of patients on probiotics had persistent IBS symptoms, compared with $73.1 \%$ of patients on placebo. The trials with the most power and best design all tended to have higher ORs of a positive effect (see Table 3).(25-27)

IBD

10 trials met our criteria and were used further in the quantitative analysis below.(40-49) Results were also mixed, but a majority of trials showed at least mild benefit of probiotics, more for maintenance of remission 
than induction of remission (most trials assessed both). In a recent meta-analysis of all published trials(50), the pooled odds ratio of induction of remission was 1.28 (95\% Cl 1.00-1.41), which favored probiotics. For maintenance of remission, the pooled odds ratio for relapse was 0.73 (95\% Cl 0.54-0.99), which favored probiotics. However, in both cases, the confidence interval is very close to 1.0, so the significance of either result is marginal.

In order to determine the balance between the abovementioned varying degrees of benefit and risk for both IBS and IBD, and to account for the heterogeneous distribution of both benefit and risk, we next proceeded to a quantitative risk-benefit analysis.

\section{METHODOLOGY OF QUANTITATIVE RISK-BENEFIT ANALYSIS}

\section{Search Strategy}

We identified studies for quantitative analysis by accessing http://www.pubmed.org. To determine all studies using probiotics to treat irritable bowel syndrome, the terms ("probiotic," "lactobacillus," "bifidobacteria", "VSL", or "saccharomyces") and "irritable bowel syndrome" were used. Results were limited to studies performed through June $30^{\text {th }}, 2014$, written in English, and entered as clinical trials. To determine all studies using probiotics to treat inflammatory bowel disease, the terms ("probiotic," "lactobacillus," "bifidobacteria," "VSL," or "saccharomyces") and ("inflammatory bowel disease" or "Crohn disease" or "Crohn's disease" or "ulcerative colitis") were used. Results were again limited to studies performed through June 30th, 2014, written in English with full article text accessible, and entered as clinical trials. The analysis and bibliography of relevant published meta-analyses were also queried to find additional studies. For initial analysis, 77 studies were found for IBS and 109 studies for IBD. The details and results of the search strategy are displayed in Figure 1. Each of the studies selected for further quantitative analysis are listed and described in more detail in Table 3. In the end, 15 studies were selected for analysis in IBS and 10 studies were selected for IBD. 
Figure 1 - Search strategy for studies to include in quantitative analysis.

Irritable bowel syndrome

Inflammatory bowel disease

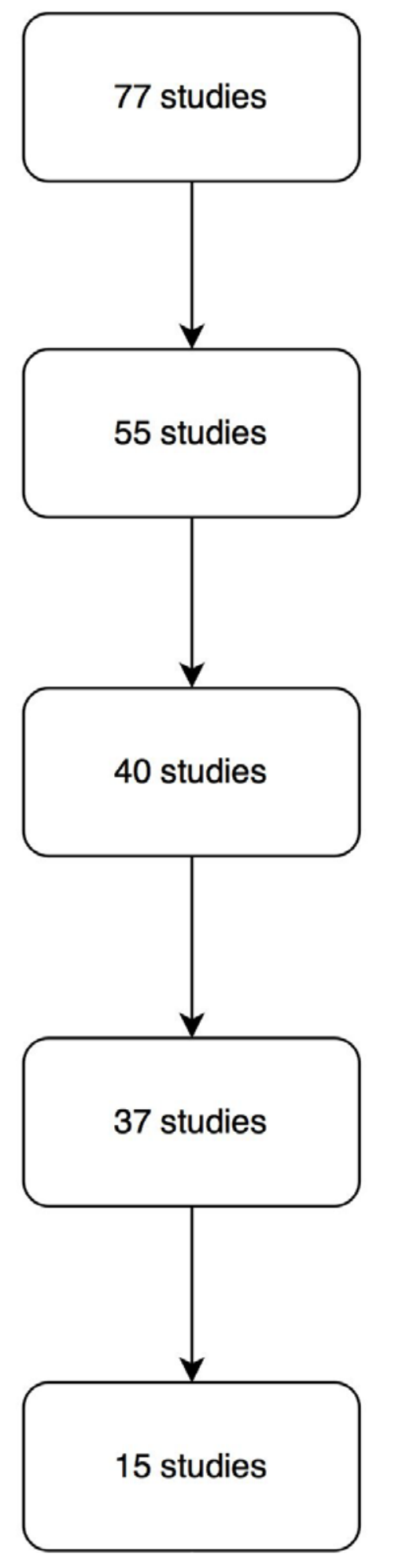

Initial query

109 studies

Randomized, double-blinded, and placebo controlled trial of an oral probiotic

\section{Specific probiotic organism enumerated}

Clinical symptoms as outcome measure

21 studies

Adverse events as an outcome

10 studies measure 
Table 3 - Description of studies selected for quantitative analysis. Benefit is the clinical endpoint for the study. Risk is the likelihood of any ADE (as defined by the study).

\begin{tabular}{|l|l|l|l|}
\hline Study (Author, Year) & $\begin{array}{l}\text { \# Experimental } \\
\text { Subjects }\end{array}$ & 95\% C.I. (Benefit) & 95\% C.I. (Risk) \\
\hline \multicolumn{4}{|l|}{ Irritable Bowel Syndrome } \\
\hline Kim 2003 & 13 & $0.51-1.67$ & $0.96-1.04$ \\
\hline Kajander 2005 & 51 & $1.12-2.44$ & $0.33-28.34$ \\
\hline Enck 2008 & 148 & $1.52-2.56$ & $0.47-0.97$ \\
\hline Hong 2009 & 34 & $0.68-1.85$ & $0.40-2.23$ \\
\hline Simren 2010 & 37 & $0.85-1.61$ & $0.96-1.04$ \\
\hline Cha 2012 & 25 & $1.14-2.56$ & $0.24-95.90$ \\
\hline Nobaek 2000 & 30 & $0.89-1.59$ & $0.96-1.04$ \\
\hline Niedzielin 2001 & 20 & $1.00-2.38$ & $0.96-1.04$ \\
\hline Sinn 2008 & 20 & $1.28-8.33$ & $0.96-1.04$ \\
\hline Dapoigny 2012 & 26 & $0.57-1.23$ & $0.96-1.04$ \\
\hline Ducrotte 2012 & 106 & $1.49-2.08$ & $0.12-71.49$ \\
\hline Guglielmetti 2011 & 62 & $1.33-2.50$ & $0.96-3.06$ \\
\hline Enck 2009 & 150 & $1.07-1.27$ & $0.96-1.04$ \\
\hline Kruis 2012 & 60 & $0.82-1.51$ & $0.76-1.62$ \\
\hline Gade 1989 & 22 & $1.01-1.89$ & $0.96-1.04$ \\
\hline Inflammatory Bowel Disease & \multicolumn{5}{l|}{} \\
\hline Kruis 1997 & 103 & $0.53-3.79$ & $0.23-1.89$ \\
\hline Rembacken 1999 & 83 & $0.69-1.22$ & $0.60-3.53$ \\
\hline Kruis 2004 & 327 & $0.73-1.58$ & $0.82-1.45$ \\
\hline Sood 2009 & 147 & $0.90-2.13$ & $0.00-0.52$ \\
\hline Tursi 2010 & 144 & $0.58-3.36$ & $0.37-2.24$ \\
\hline Matthes 2010 & 88 & $0.58-4.42$ & $0.67-1.78$ \\
\hline Prantera 2002 & 32 & $0.79-3.65$ & $0.09-1.60$ \\
\hline Bousvaros 2005 & 75 & $0.77-4.40$ & $0.33-2.00$ \\
\hline Marteau 2006 & 98 & $0.33-5.88$ & $0.36-3.01$ \\
\hline Van Gossum 2007 & 70 & $0.34-5.85$ & $0.65-1.23$ \\
\hline
\end{tabular}

\section{Risk-Benefit Analysis}

A wide variety of quantitative methods exist for risk-benefit analysis(60). Since we have little information on utilities for IBS and IBD in the literature, and most of the existing data on efficacy and risk comes from the abovementioned large number of clinical trials, we chose to use the risk-benefit plane, a method that plots the joint distribution of both risk and benefits(61). The primary advantage of this approach is that both risk and benefit are visualized simultaneously, rather than using a one-dimensional measure such as risk-benefit ratio. Furthermore, data with a large, heterogeneous distribution across both risk and benefit can be better modeled as a two-dimensional confidence region than two separate confidence intervals. 
First, we constructed a dataset using all existing clinical trials that reported both efficacy and adverse drug events for both IBS(24-38) or IBD(40-49), as described in Figure 1 and Table 1 . We sampled across the 95\% confidence intervals for each trial weighted by the size of the trial (larger trials had a larger share of sampling). When no adverse events were reported, we estimated the $95 \%$ confidence interval as a function of the number of subjects (3/N), as described previously.(62) Once the data set was complete, we simulated 5000 patients by sampling (with replacement) for 5000 iterations. Next, since the distribution of this cross-trial sample could not be assumed to have bivariate normality, we used a recently developed geometry-based method to determine confidence regions in bivariate samples. This method is more robust whether the distribution is normal or nonnormal(61), and utilizes the R package "distfree.cr." Finally, the confidence region was plotted using this package on a risk-benefit plane (RBP) to illustrate where the joint distribution of risk and benefit lies.

The end result is a geometric shape that visualizes the joint distribution of risk and benefit. So, when encountering a patient with IBS or IBD who asks about probiotics, there is a 95\% chance, based on the dataset employed, that the patient's experience will lie somewhere in that region. The shape of the curve determines where the average patient may fall: if the area of the curve is mostly above the "risk-benefit threshold" line, they have more benefit than risk; if the area of the curve is mostly below this line, they have more risk than benefit. Importantly, this does not quantify the severity of risk - only the presence of risk, nor does it quantify the type of benefit - only the presence or absence of a clinical endpoint of some kind. In the case of probiotics, the severity is often low (worse abdominal pain, for instance), so this must be taken into consideration when interpreting the results.

\section{RESULTS OF QUANTITATIVE RISK-BENEFIT ANALYSIS}

\section{IBS}

Figure 2 depicts the RBP for all published trials of probiotics for IBS. The mean risk-benefit (solid black circle) lies along the dotted line representing the risk-benefit threshold. So, the average patient will have an equal balance of risk and benefit. Overall, most of the area within the 95\% confidence region (red line) lies below the risk-benefit line, so in a slim majority of patients, risk for any ADE will outweigh benefit. Most simulated risk 
data was modeled along a normal distribution (since most trials did not report any ADEs at all), so the range of risk was much narrower than the range of efficacy, resulting in an ovoid confidence region.

Figure 2 - Risk-Benefit Plane for Irritable Bowel Syndrome. The log transformed relative risk of an ADE is plotted on the horizontal axis. The log transformed relative efficacy (in terms of relative rate of improvement in symptoms) is plotted on the vertical axis. Grey circles are individual sampled points. The black circle is the mean of all sampled points. The red line represents the approximated 95\% confidence region. The dotted line represents the threshold between a poor risk-benefit ratio (below line) and an advantageous risk-benefit ratio (above line).

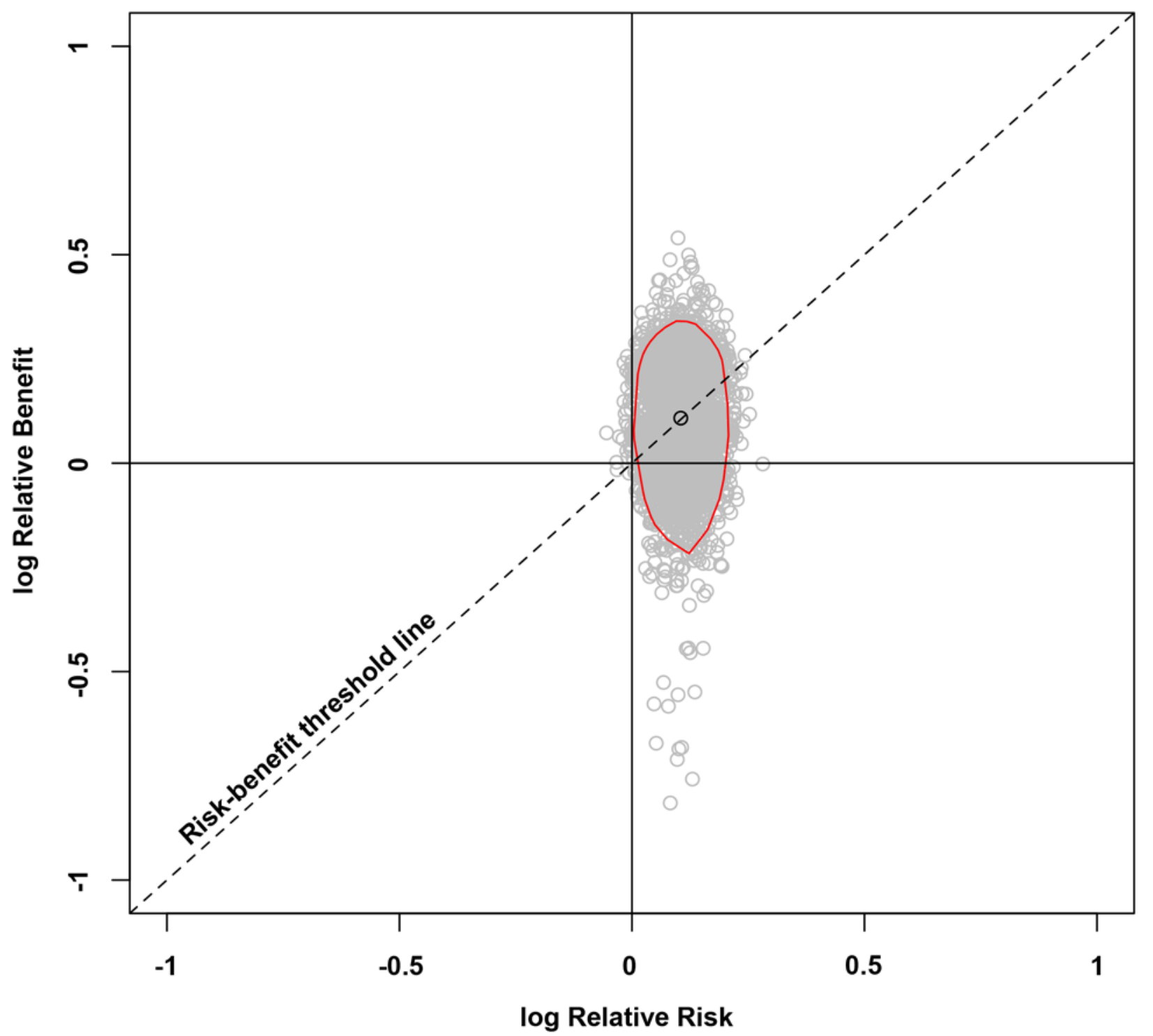


Figure 3 depicts the RBP for all included trials of probiotics in IBD. The mean risk-benefit (solid black circle) lies well above the dotted line, as does the majority of the $95 \%$ confidence region (red line). The confidence region is quite large for IBD, which occurs due to the wide heterogeneity in confidence intervals that formed the primary data source. Thus, in a general sense, probiotics seem to confer more benefit than risk for a majority of hypothetical patients, but with such a large area for the confidence region, the average patient could expect almost any risk-benefit ratio. There is noticeable heterogeneity of the confidence region (for instance, a "cloud" of simulated points in the high-risk, high-benefit range), but this should not be interpreted that any specific subpopulation exists. The method employed simply samples from all existing confidence intervals, so if one of the 10 IBD studies had a particular narrow confidence interval, simulated patients may appear to cluster in that region, but the confidence region's shape will take this variation into account. We did not perform sub-group analyses (CD vs. UC or active vs. inactive disease) due to the relative lack of high quality data on which to build a RBP for sub-groups.

Figure 3 - Risk-Benefit Plane for Inflammatory Bowel Disease. The log transformed relative risk of an $A D E$ is plotted on the horizontal axis. The log transformed relative efficacy (in terms of relative rate of maintenance of remission) is plotted on the vertical axis. Grey circles are individual sampled points. The black circle is the mean of all sampled points. The red line represents the approximated 95\% confidence region. The dotted line represents the threshold between a poor risk-benefit ratio (below line) and an advantageous risk-benefit ratio (above line). 


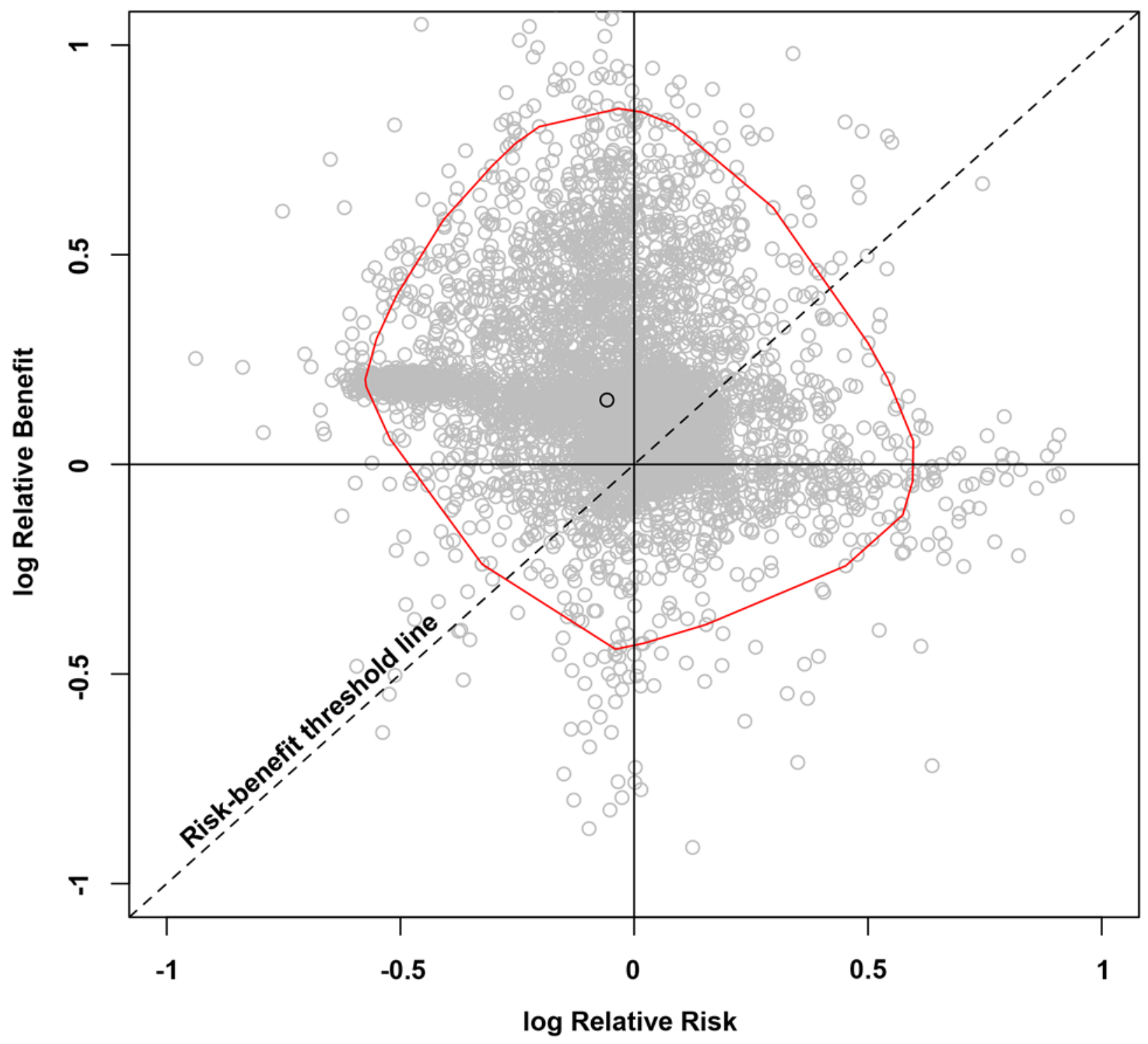

\section{DISCUSSION}

Overall, the joint assessment of risk and benefit for probiotic use in either IBS or IBD remain a significant challenge. Risk tends to be low in most patients, but so does efficacy. It is furthermore unknown what risks immunocompromised patients face when taking probiotics. Existing data on ADEs are quite poor, and most trials do not adopt a systematic approach to detecting them. 
When we queried the FAERS database, we found relatively few ADEs. In fact, given the high utilization of probiotics in the general population, the rate of reporting is quite low, and many ADEs have no clear rational association with probiotics (arthralgia, injection site pain from other medications, etc). There may be several reasons for this finding: (1) patients may not report probiotics as a medication since they are often marketed as supplements, (2) our search algorithm did not detect all reported cases, or (3) ADEs for probiotics may be so mild that they are not reported with much consistency. We suspect that patients not primed to report an ADE (as in a clinical trial) probably experience at worst minimal and vague symptoms.

When we performed quantitative risk-benefit plane analysis for both IBS and IBD, we noted a wide range of possible risk-benefit ratios, indicating that our knowledge of risk in probiotics remains poor for both of these disorders. This may be a function of the heterogeneity of organisms used across studies, but also the unique problem inherent to using live organisms as therapy for complex and heterogeneous digestive diseases. In either case, a standardized approach to ADEs in future probiotics trials will be essential to inform future treatment decisions.

In IBS, the majority of the confidence region straddles the risk-benefit threshold, and the mean risk-benefit ratio lies along the threshold. This is likely due to the fact that probiotics have low efficacy, but also low likelihood of an ADE. Since studies used in the analysis are quite broad, it is very difficult to make individual recommendations for specific patients and patient populations. On balance, it is reasonable to advise a trial of probiotics for patients with IBS.

In IBD, the confidence region is larger, owing to wider confidence intervals within and among studies. This could be a result of more varied study design, but also due to the heterogeneity of patients with IBD and the higher percentage of patients reporting ADEs. A majority of the confidence region lies above the risk-benefit threshold, and the mean risk-benefit ratio is well above this threshold as well. On balance, probiotics may be helpful in maintaining (or even inducing) remission, but the overall breadth of the confidence region indicates that uncertainty is high, so further studies are certainly needed to more accurately quantify both risk and benefit. Since we have virtually no understanding of the risk of probiotics in the immunocompromised, very 
careful consideration should be given to this population, which represents most IBD patients. It is simply unknown if there is a sub-population of IBD patients with substantial immunosuppressant-related risk. In situations where efficacy is more convincingly established (pouchitis prophylaxis with VSL\#3 in patients with a colectomy, for instance $(63,64))$, this unknown risk may be worth it, but in immunosuppressed IBD patients in general, for whom the efficacy confidence interval is broad and marginally significant, the potential severity of risk may not be worth it.

There are several limitations to our quantitative analysis. First, studies were analyzed in bloc, and no subanalysis was performed based on severity of disease, type of IBD, type of probiotic, outcomes measured, or specific ADEs assessed. Performing a more clear RBP analysis would require a larger number of homogenous studies, especially those assessing risk in a rigorous way. This is a particular challenge in probiotic clinical trials, but which is essential if we wish to expand the evidence base. Second, since several IBS studies did not report any ADEs at all, the risk sampling frequently used the normal distribution. This would tend to narrow the risk axis of the confidence region. Finally, we did not specify what type of ADE patients would have, or the severity of the ADE. Since most ADEs from probiotics are mild and not potentially life threatening, risk may be overestimated when simply specifying the rate of ADEs but not quantifying severity. It is likely that many patients would be willing to tolerate mild gastrointestinal upset and many of the other ADEs listed in Table 2. As noted above, there may also be sub-populations of immunosuppressed patient who have a similar rate of ADEs, but they might be much more severe and concerning.

One very challenging aspect of the assessment of ADEs in probiotics is the difficulty in separating disease course and drug effect. For instance, most suspected ADEs are gastrointestinal side effects, yet probiotics are most often used to treat gastrointestinal diseases, many of which have a relapsing, sporadic course as part of their natural history. Therefore, it can be quite difficult to assess whether a symptom is truly the effect of a drug or simply the effect of the disease being treated.

We believe many of the challenges of risk-benefit analysis in probiotics could be overcome by focusing future research in three ways: (1) standardize methods of assessing ADEs in patients taking probiotics, (2) limiting 
the breadth of probiotic species studied, and (3) improving the overall methodological quality of trials involving probiotics by using Guidelines for Good Clinical Practice (published by FDA as well as the World Health Organization) as are used for pharmaceutical trials.

\section{CONCLUSIONS}

Overall, the risk of probiotic use is low, but unfortunately so are benefit for both IBS and IBD. Given that many patients (and clinicians) are desperate for effective and safe interventions for these disorders, a trial of a probiotic remains a reasonable, and usually safe, practice for these diseases. Quantitative risk-benefit analysis using a risk-benefit plane indicates a confidence region shifted towards a slightly unfavorable riskbenefit in IBS, and a slightly favorable risk-benefit in IBD.

The use of probiotics in the immunocompromised host (including those on immunosuppressants for IBD) has not been well studied. Given the low likelihood of most probiotic preparations to confer a large clinical benefit to a patient, it may be wise to advise against them in this at-risk population until further safety research has been performed.

The evidence base for probiotics can be dramatically improved by both intensifying basic research into the mechanisms of probiotic efficacy and ADEs and by focusing efforts into higher quality clinical research.

\section{ACKNOWLEDGEMENTS}

The author reports no conflicts of interest related to the authorship of this manuscript. There was no specific funding for this work. The author wishes to acknowledge the Department of Pediatrics at Indiana University School of Medicine for administrative support. 


\section{BIBLIOGRAPHY}

1. National Health Information Survey - Use of Complementary Health Approaches in the United States [cited 2015 September 1, 2015]. Available from: https://nccih.nih.gov/research/statistics/NHIS/2012/naturalproducts/biotics.

2. Joint FAO/WHO Working Group Report on Drafting Guidelines for the Evaluation of Probiotics in Food. London, Ontario, Canada: April 30 and May 1, 2002.

3. Rogers NJ, Mousa SA. The shortcomings of clinical trials assessing the efficacy of probiotics in irritable bowel syndrome. Journal of alternative and complementary medicine. 2012 Feb;18(2):112-9. PubMed PMID: 22339099.

4. Boyle RJ, Robins-Browne RM, Tang ML. Probiotic use in clinical practice: what are the risks? The American journal of clinical nutrition. 2006 Jun;83(6):1256-64; quiz 446-7. PubMed PMID: 16762934.

5. Degnan FH. The US Food and Drug Administration and probiotics: regulatory categorization. Clinical infectious diseases : an official publication of the Infectious Diseases Society of America. 2008 Feb 1;46 Suppl 2:S133-6; discussion S44-51. PubMed PMID: 18181719.

6. Theunissen J, Britz TJ, Torriani S, Witthuhn RC. Identification of probiotic microorganisms in South African products using PCR-based DGGE analysis. International journal of food microbiology. 2005 Jan 15;98(1):11-21. PubMed PMID: 15617797.

7. Allen SJ, Wareham K, Wang D, Bradley C, Hutchings $\mathrm{H}$, Harris W, et al. Lactobacilli and bifidobacteria in the prevention of antibiotic-associated diarrhoea and Clostridium difficile diarrhoea in older inpatients (PLACIDE): a randomised, double-blind, placebo-controlled, multicentre trial. Lancet. 2013 Oct 12;382(9900):1249-57. PubMed PMID: 23932219.

8. Correa NB, Peret Filho LA, Penna FJ, Lima FM, Nicoli JR. A randomized formula controlled trial of Bifidobacterium lactis and Streptococcus thermophilus for prevention of antibiotic-associated diarrhea in infants. Journal of clinical gastroenterology. 2005 May-Jun;39(5):385-9. PubMed PMID: 15815206.

9. Allen SJ, Martinez EG, Gregorio GV, Dans LF. Probiotics for treating acute infectious diarrhoea. The Cochrane database of systematic reviews. 2010 (11):CD003048. PubMed PMID: 21069673.

10. Selinger CP, Bell A, Cairns A, Lockett M, Sebastian S, Haslam N. Probiotic VSL\#3 prevents antibioticassociated diarrhoea in a double-blind, randomized, placebo-controlled clinical trial. The Journal of hospital infection. 2013 Jun;84(2):159-65. PubMed PMID: 23618760.

11. McFarland LV. Evidence-based review of probiotics for antibiotic-associated diarrhea and Clostridium difficile infections. Anaerobe. 2009 Dec;15(6):274-80. PubMed PMID: 19825425.

12. Hoffmann TW, Pham HP, Bridonneau C, Aubry C, Lamas B, Martin-Gallausiaux C, et al. Microorganisms linked to inflammatory bowel disease-associated dysbiosis differentially impact host physiology in gnotobiotic mice. The ISME journal. 2015 Jul 28. PubMed PMID: 26218241.

13. Parekh PJ, Balart LA, Johnson DA. The Influence of the Gut Microbiome on Obesity, Metabolic Syndrome and Gastrointestinal Disease. Clinical and translational gastroenterology. 2015;6:e91. PubMed PMID: 26087059.

14. Shukla R, Ghoshal U, Dhole TN, Ghoshal UC. Fecal Microbiota in Patients with Irritable Bowel Syndrome Compared with Healthy Controls Using Real-Time Polymerase Chain Reaction: An Evidence of Dysbiosis. Digestive diseases and sciences. 2015 Mar 18. PubMed PMID: 25784074.

15. Oshima T, Miwa H. Epidemiology of Functional Gastrointestinal Disorders in Japan and in the World. Journal of neurogastroenterology and motility. 2015 Jul 30;21(3):320-9. PubMed PMID: 26095436. Pubmed Central PMCID: 4496905.

16. Korterink JJ, Diederen K, Benninga MA, Tabbers MM. Epidemiology of pediatric functional abdominal pain disorders: a meta-analysis. PloS one. 2015;10(5):e0126982. PubMed PMID: 25992621. Pubmed Central PMCID: 4439136.

17. Drossman DA. The functional gastrointestinal disorders and the Rome III process. Gastroenterology. 2006 Apr;130(5):1377-90. PubMed PMID: 16678553.

18. El-Salhy M. Recent developments in the pathophysiology of irritable bowel syndrome. World journal of gastroenterology : WJG. 2015 Jul 7;21(25):7621-36. PubMed PMID: 26167065. Pubmed Central PMCID: 4491952. 
19. Rao SS, Yu S, Fedewa A. Systematic review: dietary fibre and FODMAP-restricted diet in the management of constipation and irritable bowel syndrome. Alimentary pharmacology \& therapeutics. 2015 Jun;41(12):1256-70. PubMed PMID: 25903636.

20. Annahazi A, Roka R, Rosztoczy A, Wittmann T. Role of antispasmodics in the treatment of irritable bowel syndrome. World journal of gastroenterology : WJG. 2014 May 28;20(20):6031-43. PubMed PMID: 24876726. Pubmed Central PMCID: 4033443.

21. Altayar O, Sharma V, Prokop LJ, Sood A, Murad MH. Psychological therapies in patients with irritable bowel syndrome: a systematic review and meta-analysis of randomized controlled trials. Gastroenterology research and practice. 2015;2015:549308. PubMed PMID: 25802514. Pubmed Central PMCID: 4329838.

22. Marteau P, Shanahan F. Basic aspects and pharmacology of probiotics: an overview of pharmacokinetics, mechanisms of action and side-effects. Best Practice \& Research Clinical Gastroenterology. 2003;17(5):725-40.

23. Didari T, Solki S, Mozaffari S, Nikfar S, Abdollahi M. A systematic review of the safety of probiotics. Expert opinion on drug safety. 2014 Feb;13(2):227-39. PubMed PMID: 24405164.

24. Dapoigny M, Piche T, Ducrotte P, Lunaud B, Cardot JM, Bernalier-Donadille A. Efficacy and safety profile of LCR35 complete freeze-dried culture in irritable bowel syndrome: a randomized, double-blind study. World journal of gastroenterology : WJG. 2012 May 7;18(17):2067-75. PubMed PMID: 22563194. Pubmed Central PMCID: 3342605.

25. Ducrotte P, Sawant P, Jayanthi V. Clinical trial: Lactobacillus plantarum 299v (DSM 9843) improves symptoms of irritable bowel syndrome. World journal of gastroenterology : WJG. 2012 Aug 14;18(30):4012-8. PubMed PMID: 22912552. Pubmed Central PMCID: 3419998.

26. Enck P, Zimmermann K, Menke G, Klosterhalfen S. Randomized controlled treatment trial of irritable bowel syndrome with a probiotic E.-coli preparation (DSM17252) compared to placebo. Zeitschrift fur Gastroenterologie. 2009 Feb;47(2):209-14. PubMed PMID: 19197823.

27. Enck P, Zimmermann K, Menke G, Muller-Lissner S, Martens U, Klosterhalfen S. A mixture of Escherichia coli (DSM 17252) and Enterococcus faecalis (DSM 16440) for treatment of the irritable bowel syndrome--a randomized controlled trial with primary care physicians. Neurogastroenterology and motility : the official journal of the European Gastrointestinal Motility Society. 2008 Oct;20(10):1103-9. PubMed PMID: 18565142.

28. Gade J, Thorn P. Paraghurt for patients with irritable bowel syndrome. A controlled clinical investigation from general practice. Scandinavian journal of primary health care. 1989 Mar;7(1):23-6. PubMed PMID: 2657953.

29. Guglielmetti S, Mora D, Gschwender M, Popp K. Randomised clinical trial: Bifidobacterium bifidum MIMBb75 significantly alleviates irritable bowel syndrome and improves quality of life--a double-blind, placebocontrolled study. Alimentary pharmacology \& therapeutics. 2011 May;33(10):1123-32. PubMed PMID:

21418261.

30. Hong KS, Kang HW, Im JP, Ji GE, Kim SG, Jung HC, et al. Effect of probiotics on symptoms in korean adults with irritable bowel syndrome. Gut and liver. 2009 Jun;3(2):101-7. PubMed PMID: 20431731. Pubmed Central PMCID: 2852694.

31. Kajander K, Hatakka K, Poussa T, Farkkila M, Korpela R. A probiotic mixture alleviates symptoms in irritable bowel syndrome patients: a controlled 6-month intervention. Alimentary pharmacology \& therapeutics. 2005 Sep 1;22(5):387-94. PubMed PMID: 16128676.

32. Ki Cha B, Mun Jung S, Hwan Choi C, Song ID, Woong Lee H, Joon Kim H, et al. The effect of a multispecies probiotic mixture on the symptoms and fecal microbiota in diarrhea-dominant irritable bowel syndrome: a randomized, double-blind, placebo-controlled trial. Journal of clinical gastroenterology. 2012 Mar;46(3):220-7. PubMed PMID: 22157240.

33. Kim HJ, Camilleri M, McKinzie S, Lempke MB, Burton DD, Thomforde GM, et al. A randomized controlled trial of a probiotic, VSL\#3, on gut transit and symptoms in diarrhoea-predominant irritable bowel syndrome. Alimentary pharmacology \& therapeutics. 2003 Apr 1;17(7):895-904. PubMed PMID: 12656692. 34. Kruis W, Chrubasik S, Boehm S, Stange C, Schulze J. A double-blind placebo-controlled trial to study therapeutic effects of probiotic Escherichia coli Nissle 1917 in subgroups of patients with irritable bowel syndrome. International journal of colorectal disease. 2012 Apr;27(4):467-74. PubMed PMID: 22130826. Pubmed Central PMCID: 3307993. 
35. Niedzielin K, Kordecki H, Birkenfeld B. A controlled, double-blind, randomized study on the efficacy of Lactobacillus plantarum 299V in patients with irritable bowel syndrome. European journal of gastroenterology \& hepatology. 2001 Oct;13(10):1143-7. PubMed PMID: 11711768.

36. Nobaek S, Johansson ML, Molin G, Ahrne S, Jeppsson B. Alteration of intestinal microflora is associated with reduction in abdominal bloating and pain in patients with irritable bowel syndrome. The American journal of gastroenterology. 2000 May;95(5):1231-8. PubMed PMID: 10811333.

37. Simren M, Ohman L, Olsson J, Svensson U, Ohlson K, Posserud I, et al. Clinical trial: the effects of a fermented milk containing three probiotic bacteria in patients with irritable bowel syndrome - a randomized, double-blind, controlled study. Alimentary pharmacology \& therapeutics. 2010 Jan 15;31(2):218-27. PubMed PMID: 19863495.

38. Sinn DH, Song JH, Kim HJ, Lee JH, Son HJ, Chang DK, et al. Therapeutic effect of Lactobacillus acidophilus-SDC 2012, 2013 in patients with irritable bowel syndrome. Digestive diseases and sciences. 2008 Oct;53(10):2714-8. PubMed PMID: 18274900.

39. Ford AC, Quigley EM, Lacy BE, Lembo AJ, Saito YA, Schiller LR, et al. Efficacy of Prebiotics, Probiotics, and Synbiotics in Irritable Bowel Syndrome and Chronic Idiopathic Constipation: Systematic Review and Meta-analysis. The American journal of gastroenterology. 2014 Jul 29. PubMed PMID: 25070051.

40. Bousvaros A, Guandalini S, Baldassano RN, Botelho C, Evans J, Ferry GD, et al. A randomized, double-blind trial of Lactobacillus GG versus placebo in addition to standard maintenance therapy for children with Crohn's disease. Inflammatory bowel diseases. 2005 Sep;11(9):833-9. PubMed PMID: 16116318. 41. Kruis W, Fric P, Pokrotnieks J, Lukas M, Fixa B, Kascak M, et al. Maintaining remission of ulcerative colitis with the probiotic Escherichia coli Nissle 1917 is as effective as with standard mesalazine. Gut. 2004 Nov;53(11):1617-23. PubMed PMID: 15479682. Pubmed Central PMCID: 1774300.

42. Kruis W, Schutz E, Fric P, Fixa B, Judmaier G, Stolte M. Double-blind comparison of an oral Escherichia coli preparation and mesalazine in maintaining remission of ulcerative colitis. Alimentary pharmacology \& therapeutics. 1997 Oct;11(5):853-8. PubMed PMID: 9354192.

43. Marteau P, Lemann M, Seksik P, Laharie D, Colombel JF, Bouhnik Y, et al. Ineffectiveness of Lactobacillus johnsonii LA1 for prophylaxis of postoperative recurrence in Crohn's disease: a randomised, double blind, placebo controlled GETAID trial. Gut. 2006 Jun;55(6):842-7. PubMed PMID: 16377775. Pubmed Central PMCID: 1856210.

44. Matthes H, Krummenerl T, Giensch M, Wolff C, Schulze J. Clinical trial: probiotic treatment of acute distal ulcerative colitis with rectally administered Escherichia coli Nissle 1917 (EcN). BMC complementary and alternative medicine. 2010;10:13. PubMed PMID: 20398311. Pubmed Central PMCID: 2861635.

45. Prantera C, Scribano ML, Falasco G, Andreoli A, Luzi C. Ineffectiveness of probiotics in preventing recurrence after curative resection for Crohn's disease: a randomised controlled trial with Lactobacillus GG. Gut. 2002 Sep;51(3):405-9. PubMed PMID: 12171964. Pubmed Central PMCID: 1773351.

46. Rembacken BJ, Snelling AM, Hawkey PM, Chalmers DM, Axon AT. Non-pathogenic Escherichia coli versus mesalazine for the treatment of ulcerative colitis: a randomised trial. Lancet. 1999 Aug 21;354(9179):635-9. PubMed PMID: 10466665.

47. Sood A, Midha V, Makharia GK, Ahuja V, Singal D, Goswami P, et al. The probiotic preparation, VSL\#3 induces remission in patients with mild-to-moderately active ulcerative colitis. Clinical gastroenterology and hepatology : the official clinical practice journal of the American Gastroenterological Association. 2009 Nov;7(11):1202-9, 9 e1. PubMed PMID: 19631292.

48. Tursi A, Brandimarte G, Papa A, Giglio A, Elisei W, Giorgetti GM, et al. Treatment of relapsing mild-tomoderate ulcerative colitis with the probiotic VSL\#3 as adjunctive to a standard pharmaceutical treatment: a double-blind, randomized, placebo-controlled study. The American journal of gastroenterology. 2010 Oct;105(10):2218-27. PubMed PMID: 20517305. Pubmed Central PMCID: 3180711.

49. Van Gossum A, Dewit O, Louis E, de Hertogh G, Baert F, Fontaine F, et al. Multicenter randomizedcontrolled clinical trial of probiotics (Lactobacillus johnsonii, LA1) on early endoscopic recurrence of Crohn's disease after lleo-caecal resection. Inflammatory bowel diseases. 2007 Feb;13(2):135-42. PubMed PMID: 17206696.

50. Shen J, Zuo ZX, Mao AP. Effect of probiotics on inducing remission and maintaining therapy in ulcerative colitis, Crohn's disease, and pouchitis: meta-analysis of randomized controlled trials. Inflammatory bowel diseases. 2014 Jan;20(1):21-35. PubMed PMID: 24280877. 
51. Jacobs SE, Tobin JM, Opie GF, Donath S, Tabrizi SN, Pirotta M, et al. Probiotic effects on late-onset sepsis in very preterm infants: a randomized controlled trial. Pediatrics. 2013 Dec;132(6):1055-62. PubMed PMID: 24249817.

52. Fernandez-Carrocera LA, Solis-Herrera A, Cabanillas-Ayon M, Gallardo-Sarmiento RB, Garcia-Perez CS, Montano-Rodriguez R, et al. Double-blind, randomised clinical assay to evaluate the efficacy of probiotics in preterm newborns weighing less than $1500 \mathrm{~g}$ in the prevention of necrotising enterocolitis. Archives of disease in childhood Fetal and neonatal edition. 2013 Jan;98(1):F5-9. PubMed PMID: 22556209.

53. Lin HC, Hsu CH, Chen HL, Chung MY, Hsu JF, Lien RI, et al. Oral probiotics prevent necrotizing enterocolitis in very low birth weight preterm infants: a multicenter, randomized, controlled trial. Pediatrics. 2008 Oct;122(4):693-700. PubMed PMID: 18829790.

54. Serce O, Benzer D, Gursoy T, Karatekin G, Ovali F. Efficacy of Saccharomyces boulardii on necrotizing enterocolitis or sepsis in very low birth weight infants: a randomised controlled trial. Early human development. 2013 Dec;89(12):1033-6. PubMed PMID: 24041815.

55. Dani C, Biadaioli R, Bertini G, Martelli E, Rubaltelli FF. Probiotics feeding in prevention of urinary tract infection, bacterial sepsis and necrotizing enterocolitis in preterm infants. A prospective double-blind study. Biology of the neonate. 2002 Aug;82(2):103-8. PubMed PMID: 12169832.

56. Barraud D, Blard C, Hein F, Marcon O, Cravoisy A, Nace L, et al. Probiotics in the critically ill patient: a double blind, randomized, placebo-controlled trial. Intensive care medicine. 2010 Sep;36(9):1540-7. PubMed PMID: 20502866.

57. Manzoni P, Lista G, Gallo E, Marangione P, Priolo C, Fontana P, et al. Routine Lactobacillus rhamnosus GG administration in VLBW infants: a retrospective, 6-year cohort study. Early human development. 2011 Mar;87 Suppl 1:S35-8. PubMed PMID: 21295418.

58. Administration FaD. FDA Adverse Event Reporting System (FAERS): Latest Quarterly Data Files 2014 [August 12th, 2014].

59. Ford AC, Moayyedi P, Lacy BE, Lembo AJ, Saito YA, Schiller LR, et al. American College of Gastroenterology monograph on the management of irritable bowel syndrome and chronic idiopathic constipation. The American journal of gastroenterology. 2014 Aug;109 Suppl 1:S2-26; quiz S7. PubMed PMID: 25091148.

60. Guo JJ, Pandey S, Doyle J, Bian B, Lis Y, Raisch DW. A review of quantitative risk-benefit methodologies for assessing drug safety and efficacy-report of the ISPOR risk-benefit management working group. Value in health : the journal of the International Society for Pharmacoeconomics and Outcomes Research. 2010 Aug;13(5):657-66. PubMed PMID: 20412543.

61. Shaffer ML, Watterberg KL. Joint distribution approaches to simultaneously quantifying benefit and risk. BMC medical research methodology. 2006;6:48. PubMed PMID: 17038184. Pubmed Central PMCID: 1630697.

62. Ho AM, Dion PW, Karmakar MK, Lee A. Estimating with confidence the risk of rare adverse events, including those with observed rates of zero. Regional anesthesia and pain medicine. 2002 Mar-Apr;27(2):20710. PubMed PMID: 11915070.

63. Gionchetti P, Rizzello F, Helwig U, Venturi A, Lammers KM, Brigidi P, et al. Prophylaxis of pouchitis onset with probiotic therapy: a double-blind, placebo-controlled trial. Gastroenterology. 2003 May;124(5):12029. PubMed PMID: 12730861.

64. Mimura T, Rizzello F, Helwig U, Poggioli G, Schreiber S, Talbot IC, et al. Once daily high dose probiotic therapy (VSL\#3) for maintaining remission in recurrent or refractory pouchitis. Gut. 2004 Jan;53(1):108-14. PubMed PMID: 14684584. Pubmed Central PMCID: 1773918. 